\title{
1. Introduction: poverty, resilience and the European crisis
}

\author{
Markus Promberger, Marie Boost, Jennifer \\ Dagg and Jane Gray
}

\section{RESILIENCE: A THREEFOLD QUESTION}

This book is about those few households which are in poverty, or close to it, but manage to get by relatively and sometimes unexpectedly well. Not necessarily in the sense of standard understandings of a decent life, but in terms of getting-by-better than most of their peers, despite the range of adversities and crises that they face. This book explores what makes them, or how they make themselves, resilient. It seeks to know how they, and we, can learn from resilient processes and practices. As a result, this book develops new concepts for poverty research in order to broaden the analytical lens (poverty is not only an income problem) and overcome the important, but often dominant deficit approach. This is achieved by exploring various dimensions of how families and households in, or close to poverty actually get by, as well as how and why some of them do so better than others under similar circumstances.

There are three main questions explored in this book: is there social resilience among households at the brink of poverty? How does it work (or not), and what are its respective resources, conditions, restraints, limits and risks? And, what can social policy learn from these findings to aid crisis?

In part, this book reflects the social effects in Europe of the global economic crisis of 2007, or the 2008 Great Recession, and beyond. It refers to the period in which the global financial market was in turmoil (the 'subprime crisis'), caused by shifting speculative risks, post-democratic elite formations, dis-information, irresponsibility and specific decouplings (see Sennett 2012; Jackson 2009; Crouch 2011) that resulted in state budgets having to support the financial sector in order to maintain economic stability. This shift of risk overburdened many state budgets with some states forced to apply for international support. In many cases, this support was conditional upon national governments implementing fiscal reforms and introducing austerity policies, most prominent in Greece and Spain. Such conditions resulted in increased 
privatization of state properties, drastic cuts in expenditure related to social investment and employment policy, public services including health, public sector labour, and even education. This period saw tremendous wealth redistribution in favour of the international financial sector, ultimately compensating them for moral and economic failures at the cost of ordinary middle- and low-income people.

This book is in part also a response to the fact that European anti-poverty policies have not been able to reduce poverty substantially. Even since the Lisbon 2002 anti-poverty goals and the implementation of 'activating' social policies - which increased work pressure, reduced transfer payments and public expenditures and increased thresholds for eligibility into social programmes - there has not been much change in overall poverty rates (see Chapter 7). There has been little effect apart from turning some unemployment into precarious labour, often without the intended budget savings (see Promberger 2015 for the German case). There is still considerable poverty in European welfare states (see Chapter 3). Indeed, poverty research needs some fresh answers. We know quite a lot about poverty thresholds, income poverty, and the size and dynamics of poor populations. There is some evidence of the efficiency and effectiveness of anti-poverty programmes. However, there is still just a small thread of research on how living conditions are transformed as a result of life processes and practices, and the differences between coping or transforming poverty situations.

To describe getting by under adversity, terms like coping or adapting have been introduced. Yet one specific concept specifically targets getting-by-better, and this is the concept of resilience. It has just recently crossd the borders of science and entered the socio-political discourse, mainly in the UK and partly at EU level. The genealogy of the 'resilience' concept will be discussed more broadly in Chapters 4 and 5. However, it has to be emphasized here that the concept poses both potentials and drawbacks when it becomes a discursive register within the political realm. Simplistically, it can mean that some units of observation are successfully beating the odds while others are not. It promises to restore belief in human nature and survival ability, in the 'ordinary magic' (Masten 2001) and inherent powers of human individuals, groups and families, and to provide a general solution to crises of various kinds, including natural disasters, economic downturns, or deprived childhoods. All the while, the concept poses a drawback - as an argument misused to blame vulnerable people for not being resilient, and distracting observers from the institutional failures surrounding crises. By entering the political discourse, and being exposed to political rhetoric, it shares the fate of many scientific concepts like class, identity, or even society. At the beginning of the project underlying this book, we encountered criticisms and warnings of various kinds on the concept of resilience, nevertheless, we decided not to abandon it but to stick 
to the scientific use of the concept and develop its social scientific explanatory power. Similar to psychology, where resilience has been attributed to empirically identifiable dimensions, such as salutogenetic factors (Antonovsky 1996; Lösel and Bender 2003), social resilience - as we conceive it - is specifically related to the observable practices and resources used by the resilient households observed. These observations structure the discussion throughout the chapters in this book.

\section{DEVELOPMENT OF THE BOOK AND THE UNDERLYING RESEARCH}

Given the European crisis, the European Commission issued a call for research proposals in 2013 under its 7th Framework Programme (FP7) entitled 'Citizens' Resilience in Times of Crisis'. This was inspired by developments in different research fields such as disaster recovery, terrorism, ecosystems and disadvantaged communities. A group of researchers from nine European countries, of which the editors of this book were part, successfully applied for three years funding, which was granted from early 2014 to early 2017 under the project title 'Patterns of resilience during socioeconomic crises among households in Europe' (RESCuE). The chapters in this book contain results from six years of collaborative research on the resilience of households in or close to poverty, completed by more than 30 researchers from nine European countries.

The research, development and transference of the concept of resilience for use within the discipline of sociology, along with its application for sociological poverty research has been one of the ground breaking achievements of this book.

The main hypothesis of the project was that resilience in poverty, where it existed at all, was based on the practical mobilization of social, economic and cultural resources. These practices or resources are not necessarily obvious, they are not on the radar of standard poverty administration and research, they are not easy to mobilize nor are they available to many households. Resilient households are able to identify, access and mobilize such resources when paid labour - the standard resource of non-propertied households - is lost, unavailable or insufficient for the household's livelihood. It has to be said that this approach of exploring household practices has been an issue in social history (Malcolmson 1989), labour and economic anthropology (Wallman 1979), and in development research approaches like the livelihood concept. Despite this, studying household or other small-scale socioeconomic practices has seldom been associated with resilience (except by a few, namely Béné et al. 2011), and is more commonly associated with similar concepts like sustainability or livelihood. These not only share a mixed field of meaning with the resilience 
concept, but also comprise analytical, teleological and political aspects, as resilience does. Resilience itself, already well established in psychology and ecosystems research, has become a hot topic in disaster research and social geography. To begin to transfer resilience into a sociological approach, one needs to understand it in a more sociological than psychological way (see Chapter 4), that is, in a way that mostly investigates social, cultural or economic resources or affordances at hand that are mobilized and utilized within certain patterns of practice (Haslanger 2018).

The research teams focused on studying resilient (and some non-resilient) households, but not larger communities, social groups or individuals, for various reasons. First, most individuals do not live alone but in a shared household, which normally centres on family relationships. Within that household, they usually share their lives and resources and take decisions together, no matter how equal or asymmetric this may be. Thus, it does not make sense to investigate the resilience of individuals only and treat their households and families as external conditions when we actually have an interactive co-production of living patterns and conditions within the household. The second reason is a substantial theoretical and practical problem: if the level of observation moves beyond individuals and families, into larger communities, the validation of outcome - like surviving or beating the odds - will also move to an elevated level. This shift may hide cases where communities may well survive or even thrive, but at the cost of selected members or sub-groups. The third reason is that social policy usually addresses individuals, families and households and not larger communities, although there might be political agendas in that direction. Looking at larger groups or wider social aggregates can make some limited sense for considering changes in ecosystems of plants and animals, but certainly does not make sense in the ethical framework of equality, social justice, and civil and human rights within which European social policy acts (see also Chapter 4).

Accordingly, the household is the economic or institutional framework for observing resilience as we understand it. A private household is a basic socioeconomic unit with a local centre of at least partial or temporal cohabitation. It is involved in external relations to markets and institutions with the relative absence of market relations internally. Households are conceived as the basic economic units of consumption and reproduction. For most of human history, and still for most people around the world, they also are the basic unit of production. Family relationships form the kernel of most households. As implied in the RESCuE project, family is defined as close interpersonal ties, often involving cohabitation and resource sharing on the basis of non-market intimate and/or genealogical relations. This can include couples married or unmarried, hetero-, homo- or non-sexual, with or without children, three or more generation families, patchwork families, single parent families, wider 
kin and affective peer cohabitation. Family may include members which are temporarily or permanently absent, but still related. Further, under certain circumstances we can even talk about family when people interviewed just call themselves a family. ${ }^{1}$

Concerning poverty, the RESCuE project uses a multilayered definition. This starts with the double definition of poverty by Georg Simmel (1992[1908]): first, being poor means having significantly lower means of living than one's respective peers. Second, being poor means being identified as such by wider society. The latter, at least, is quite complex. Simmel explicitly thought of the early roots of the welfare state defining the poor and creating institutions to support them. Being poor from the perspective of society can occur through being registered for welfare or receiving donations, but also by public begging, being homeless, living in an area which is perceived to be inhabited by poor people, working in jobs known to be badly paid, becoming evicted or something else. But being socially identified as poor can also happen differently, like having an income below the - socially defined - poverty line or showing signs of deprivation without seeing oneself as poor in the strict sense. And, certainly, being poor does not necessarily mean receiving welfare benefits, nor to be jobless. The working definition of poverty for the project researchers and authors of this book was a pragmatic and conventional one - having a monetary income of up to 60 per cent of the national median needs-based net household income. This definition is used as a standard by national governments and supranational authorities around the world. Nevertheless, as this definition is stricter than lived experience, it needs to be amended by two considerations. First, two households with the same monetary income may have very different assets or may experience different degrees of undersupply or deprivation. This is the reason why quantitative poverty researchers often prefer to talk about income poverty, material deprivation or welfare recipiency instead of poverty in general, and increasingly include non-monetary indicators in measures of poverty (Nolan and Whelan 2018). Second, a very small difference in income may make one household count as poor in terms of income, and the other one not, although there may not be any remarkable difference in their situation. Third, there are households below the income poverty line who manage to live on their own income and do not claim benefits, and households with the same monetary income but from welfare state sources. This gives reason to talk about socioeconomic vulnerability in low-income situations instead of talking about poverty in the strict sense. Pragmatically, most contributions in this book nevertheless talk about poverty, where the concern is about living on an income, self-provided or not, above but close to, on or below the poverty line. ${ }^{2}$

It has to be noted that these working definitions used by the project team are intended to be precise only in so far as is necessary to become operable, to still keep a certain openness at the 'fringes', instead of being so precise that 
they are completely free of logical contradictions and ambiguities. Concepts are the main element of giving structure to and speaking about observations, and they refer to inherent characteristics of the observed elements as well as to the perspective of the observers. Empirical operability of a concept means that it includes a certain level (neither maximum nor minimum) of variation and is sharp enough to draw distinctions, although not perfectly distinctive to shed any similarities between observed units.

\section{METHODOLOGY AND DESIGN OF THE PROJECT}

As there has not been much research on poverty and resilience, and even less so at household level, an explorative qualitative approach was taken. Nevertheless, in order to enable a certain level of generalizability - in terms of saturation (Glaser and Strauss 1967) and coverage of varieties, not in terms of statistical representativeness - a substantial number of case studies were included and a contrastive pattern of sampling was implemented. The ex-ante contrasting dimensions were:

- Contrastive country selection in order to cover different types of welfare states according to an expanded Esping-Andersen model (Esping-Andersen 1989), including a Mediterranean and a post-socialist type of welfare state alongside the liberal, conservative and social-democratic models. The United Kingdom and Ireland have been selected to represent the liberal welfare state, Finland for the Scandinavian or social-democratic model, Poland for the post-socialist type and Germany as a conservative welfare state. Spain, Portugal, Greece and Turkey represent the Mediterranean type, intendedly represented by four countries, with Turkey also standing for what could be called a kind of 'tiger economy' or emerging welfare state in crisis, as well as a non-EU welfare state.

- Both urban versus rural settings were observed, with rural meaning not a prevalence of agricultural life, but rather distance to urban agglomerations and expected variations in access to land and nature, density of settlements, self-owned housing, community relations and so on.

- Country and area selection were moreover considered to cover different degrees of socioeconomic impact of the crisis. For instance, Poland, Germany, Finland and Turkey were chosen to represent countries which have not been affected as severely in terms of their national economy and labour market developments. Nevertheless, they have areas or social groups affected by the crisis of 2007 and after, or group-specific crises, or structural crises. In those countries, areas with increased poverty rates, above average labour market problems or similar symptoms were chosen for the case studies. In Finland, the Finnish Lapland was chosen as an 
economically and environmentally critical region - the relative decline of wood-related industries, an increasing vulnerability of traditional reindeer herding due to climate change (Vuojala-Magga et al. 2011), and the generally harder living conditions of the far North. In Turkey, a region in a Kurdish populated area was selected according to ongoing ethnic and political tensions imposing an increasing framework of risk, while in the other selected area a huge migrant inflow from Syria resulted in an above average vulnerable population. Poland and Germany, relatively unscathed in the Great Recession of 2008 and after, nevertheless had poverty populations, those left behind by the speed of transformation and modernization in Poland, and by German unification and its economic perturbances at a regional level. Ireland, Spain and Portugal, although they belong to different welfare state types, shared a relatively quick macroeconomic recovery at the expense (to varying degrees) of the welfare state and social policy budgets and thus the socioeconomically vulnerable population. While Germany and the UK shared a relatively low crisis impact, and a poor population of similar and persistent size, welfare state activities and intensities differed considerably (see Lohmann and Andreß 2008; Taylor-Gooby et al. 2017). Last but not least, Greece was chosen as having suffered the heaviest impact of the crisis, including the meltdown of public employment and welfare state provisions to minimal levels, and - like Ireland for a short time - exposing state budget control to the EU 'troika' in order to obtain budget creditability.

- Gender was included as a criterion, not only in terms of having roughly the same proportion of female and male persons interviewed as representative of the household, but also to assess broader socioeconomic shifts related to the financial crisis on the dynamics, patterns and practices of men and women, within and outside the family.

More contrasting dimensions were included where they emerged through the sampling process, which was organized to coincide with interviewing and the first tentative analysis. During sampling, different sampling ways had to be employed to achieve a variation of cases as wide as possible. The fieldwork began by contacting local experts from welfare authorities, charities and civil society organizations, asking them to suggest cases which match a first-order concept approximating the concept of resilience - like getting by well in poverty. Then, the number and kind of such experts were varied at later stages of the fieldwork - through snowballing of interviewed household members and local experts - for collecting more and different cases.

Not only were sampling and ways of access deliberately varied and contrasted, but also the methods of data collection. Data collection took place at four levels with different, yet simultaneously, overlapping methods: (1) Macro 
data at macro level (Europe and country); (2) expert information and open observation at regional and local level; (3) qualitative biographical interviewing (Schütze 1983); (4) interviewees' self-taken photographs (Noland 2006; Kolb 2008) and photo elicitation interviews (Harper 2002; Wuggenig 1990) at household level, but with individual components, as well as participant observation at household level. Triangulation (Flick 2011) or a multi-method approach would be an appropriate label for the procedures applied to collect information. These consisted of analysis of documents and statistics, expert knowledge, household narratives of representative members, and non-verbal information gathered and composed by the interviewees and their families including photographic fieldwork and researchers' participant observations.

Many of the areas where we did our research were well known to us beforehand, yet not all of them, thus, we did actually share the lives of our respondents for longer periods in some cases, and short periods in other cases. Furthermore, we had to apply some loose structures such as choice of methods, development of thematic checklists, and the use of ex-ante and second-order concepts (like resilience) in order to achieve a framework as open and consistent as possible in order to allow for cross-national (and cross-language/cultural) comparison.

Under these presumptions, considerations and conditions, it was decided to do interviews with local experts in the case study areas, and, after doing 'ethnographic walks' (Flick et al. 2018) to explore the surroundings and localities, conduct a first wave of narrative interviews in 24 households in each country. These were divided between rural and urban case study regions. Country wise, 12 of these households were selected to participate in the photographic fieldwork and subsequent photo elicitation interviews. Criteria included interviewees' consent to participate in this second step, a certain minimum level of responsiveness, mutual trust relations in the foregoing interview situation, and making sure to involve different and contrasting constellations and observations.

Interviewing in the first wave was based on a thematic checklist but was also open to issues raised by the interviewee. This was achieved by commencing with a narrative phase, and when the narrative potential was exhausted, shifting to tackle the topics of the checklist which had not already been addressed. The photographic fieldwork (see Chapter 13) was done with simple digital cameras provided by the research teams and gifted to the participants together with an inspirational guideline developed by the research team. This inspirational guide provided open topics that could be photographed by the participants, formulated in everyday language - my home, family and friends, work, my neighbourhood, what I like, what I dislike, leisure, a day of feast, an everyday meal, a source of strength and similar topics. The guideline was distributed with encouragement to the photographers to address other or different topics of their own choice as well as, or instead of, the ones provided on the 
guide. The number of photographs per family/household was not limited by the interviewers and free to choose by the participants. After four to six weeks, a photo elicitation interview followed, mainly structured by the interviewees' explanations of their photographs to the interviewer. Most interviews took place in the households of the study participants, a small number in other places suggested by the interviewees - the latter not only in order to avoid bringing the interviewer into bad housing conditions or other open signs of poverty, but also to be seen together with strangers in reputable public places like cafes or community cultural centres. All thematic checklists, inspirational guidelines, selection of places, or choice of incentives were 'localized' - which means they were translated into the respective language, adapted to local cultural conditions to a certain extent, walking the thin line between keeping up homogeneity to ensure comparability, and allowing for heterogeneity to adapt to local conditions. Complete verbal transcriptions of the interviews were done in the original language by or under the control of the local research teams.

During these procedures, between 2014 and 2015, a body of more than 70 expert interviews and more than 330 first and second wave interviews were conducted and recorded in 220 households, leading to almost 10,000 pages of transcripts with more than 1,000 photographs contributed by participants. A small number of households investigated turned out to lack signs of resilience and served as comparative cases, while the majority of the selected households indeed showed resilience, albeit in very different manners and degrees. In some countries this comparison of non-resilient and resilient households was expanded by including cases from preceeding research projects with similar designs, like the IAB (Institute for Employment Research) qualitative poverty studies in Germany (Hirseland and Ramos Lobato 2010, p. 41) or other foregoing work like the FP7 project 'SPHERE' on identities in areas of industrial decline in Poland, Germany, Turkey and Spain (see Kirk et al. 2011).

Area, local and expert information, interviews and photographs were then analysed in two parallel processes. The first process was a dimensional analysis that investigated the collated cases for the thematic fields considered relevant ex ante for theoretical reasons, like the three families of resources (social, cultural, economic), with gender and ethnicity as the main intersectionalities, together with a spatial dimension, and the relation to welfare state institutions. The second process was a typological analysis. This was based on case profiles comprising visual and interview materials, organizing the cases along inductive and dimensional heterogeneities and homogeneities. The dimensional analysis was largely a collaboration between research teams, as cases were compared and drawn together jointly and interactively, in copresence or through correspondence of the project consortium, organized along the thematic or dimensional structure of macro developments and crisis impact 
such as socioeconomic practices (Chapter 6), cultural and community patterns (Chapters 7 and 11), biographical dimension (Chapter 8), spatial dimension (Chapter 10), the relations to welfare state and social economy activities (Chapters 12 and 15), and intersections with gender, ethnicity and migration issues (for gender see Chapter 9). As a first step, work consisted of local teams collecting, analysing and reporting relevant dimensional findings of their respective country. This process enabled analysis, synthesis, explanation and translation of findings into English. Following this, one or two commissioned lead teams further analysed and synthesized the national reports produced by each country to create an international report on a particular dimension. Furthermore, classificatory and typological analysis was mainly undertaken by the UK team where socioeconomic practices are concerned (see Chapter 6), and by the German team, who created a tentative multidimensional typology of resilience (see Chapter 14). Furthermore, classificatory and typological analysis has been undertaken on several topics like community, household practices, household types, welfare state change and forms of social economy.

\section{OUTLINE OF THE BOOK}

The book is divided into four parts. Part I begins with this introduction. Chapter 2, by Promberger and Vuojala-Magga, provides a microsociological and cultural anthropological perspective to explore concepts that enable a study of household resilience. It suggests conceiving of resilient practices of poor households as being economic, cultural and social at the same time, and identifies their usually non- or low-commodified nature, such as in sharing and gift exchange, or mutual help. The chapter emphasizes the affordances and enskilment of small-scale routinized habits and practices that are embedded in cultural and social patterns, which in turn produce social and cultural outcomes aside the economic one. Chapter 3, written by Estêvão, Calado and Capucha, investigates the impact of the global financial crisis, meanwhile called the Great Recession, in Europe and offers a macro European perspective. It uses statistical indicators to compare the effects of the crisis on private households in the nine countries investigated - Finland, Portugal, Ireland, Greece, Poland, United Kingdom, Spain, Turkey and Germany.

Part II of the book focuses on different perspectives on the concept of household resilience. Chapter 4, by Boost, Promberger, Meier and Sowa, examines the genealogy and concept of resilience and the potential to transfer it from fields like psychology, cultural geography or ecosystems research into sociology and social policy research in general, as well as to poverty research in particular. Chapter 5, written by Calado, Capucha, Dagdeviren, Donoghue and Estêvão, adds another critical perspective to resilience by rejecting heroic uses of the concept and emphasizing the limitations and risks of resilience. 
Part III brings together different empirical dimensions of resilience. First, Chapter 6 by Dagdeviren and Donoghue examines and classifies the observed socioeconomic practices of resilient and less resilient households in order to develop the thesis that resilience of poor households is mainly coping and adaption to adverse living conditions, with little transformation. Chapter 7 , by Gnieciak and Wódz, explores cultural practices and resources involved in the life of resilient households, from knowledge and skills to cultural affiliations, norms and values. Chapter 8 , by Dagg and Gray, develops a comparative biographical analysis of resilience in the lives of Europeans experiencing hardship after the economic crisis, using concepts from the life course perspective in social science. It shows how some participants sought to recover a sense of agency and positive anticipation through the reconfiguration of their biographical projects, often in ways that involved the adoption of new ethical frameworks. Chapter 9, by Castrillo, Martín, Arnal and Serrano, focuses on the intersecting dimension of gender and inequality in resilient households. Chapter 10, by Aytekin and Şengül, discusses the spatial aspects of resilience using three analytical levels from the body to the global. Chapter 11, by Serrano, Revilla, Martín and de Castro, questions whether or how communities play a role in resilience formation. Chapter 12, by Mandrysz and Wódz, likewise questions the role of social economy organizations; given the multifacetedness of both concepts and field which deserved a research project of its own, they decided on a descriptive analysis. Lastly, Chapter 13, by Bosch and Promberger, discusses how the aesthetic practices of participants reveal a level of self-reliance that can assist with coping, or even transforming, critical situations and circumstances towards a resilient way of life.

Part IV of the book provides the conclusions and implications of the research findings. Chapter 14, by Promberger, Boost and Müller, synthesizes the empirical analysis into a multidimensional typology of resilient low-income households. It shows that resilience may consist of very different clusters of practices, habits and resources which accumulate for different types of household resilience, which show different forms and levels of outcomes - some of them including more transformative capacities than others. This can lead to remarkable differences in terms of availability of resources, quality of life, welfare dependency and life satisfaction. Chapter 15, by Kambouri, Marinoudi and Petraki, asks whether the impact of the crisis and the resilience patterns shown in Greece, Spain and Portugal indicate an erosive pattern characteristic of the Mediterranean or Southern European type of welfare state. Chapter 16, by Tennberg and Vola, shows how the resilience concept and findings relate to the European policy discourse. This leads into a set of tentative yet insightful policy implications. Finally, in Chapter 17, the editors draw conclusions in both scientific terms and from a social policy perspective. 
It may be important for the reader to know that international comparative projects with a qualitative empirical approach require a certain empirical openness not only in terms of concepts, methodology and theory, but also in the interpretations made and the conclusions drawn. This counts even more when there are more than 30 researchers from different countries and disciplinary backgrounds taking part in the research. This variance necessarily develops different perspectives, but luckily, in the case of RESCuE, with a large overlap. Saying that, differences should not be neglected. Controversies existed, primarily about the concept of resilience itself. For instance, resilience usually is a clear second-order concept in the terminology of Alfred Schütz, thus limited to the sphere of scientific observation and interpretation and not part of the knowledge of the observed. But, particularly within the liberal countries, resilience is a political concept operational in a neoliberal context, such as the UK 'Big Society' programme. These tensions may be identified in Chapters 3 and 4 and are also ongoing in publications outside the book (see Dagdeviren et al. 2016, 2017; Promberger 2017; Revilla et al. 2018). Nevertheless, most of the researchers shared the opinion that using the concept of resilience can bring forward new aspects and shed new light on poverty and social policy.

The second difference was a philosophical one with empirical implications: is resilience an inherent quality in most human beings, but manifesting at different times in different biographies, being hindered or ameliorated by socio-historical forces and structures? This is an implicit understanding in youth psychology, educational studies (e.g. Ungar and Liebenberg 2005; Dolan, 2012) and more broadly within the life course perspective in social science (see Elder 1998, p. 9). Or should we think of resilience as rare, especially under extreme adversities, like Viktor Frankl (1985[1946]) did? Although fundamental in its anthropological meaning, this difference did not prove too relevant in the empirical realm of limited data and observations when both positions observed that resilience manifested itself in different degrees, differently across cases within different periods of time and under different conditions. However, the difference between these two perspectives does have significant implications when it comes to establishing empirical criteria for evaluating whether and how any individual household or individual may be deemed 'resilient'. Two of the editors of this volume (Boost and Promberger) subscribe to the second perspective, assuming that resilience always presents itself differently depending on varying contextual and processual conditions, but usually occurs rarely, likely to be true of only a small minority of poor households in Europe. Dagg and Gray subscribe to the first perspective, treating resilience as a process with identifiably 'better' or 'worse' outcomes for individuals, households and communities, depending on biographical and historical timing, and on variations in enabling and constraining social contexts. According to this perspective, resilience is likely to be more common 
than not - albeit at a price - over extended periods of time. Promberger and Boost nevertheless think that, beyond the mentioned etiological difference, this dissent is less about the undoubted procedural nature of resilience and more about scaling and thresholds - and their representation. Do we talk about little, less or more resilience in a certain case and at a certain point of time, or do we use an implicit or explicit context-dependent threshold above which we talk and below which we don't talk about resilience?

The third difference was how to estimate and interpret the power of socioeconomic structures and frameworks executed on vulnerable households - like class, gender, ethnicity - and the degree of freedom and the options for acting outside, beneath or below these structures, as well as on the chances and attempts of success of such unorthodox practices. Is it only the state which can mend the detrimental effect of a crisis on low-income households? What exactly is and should be the role of the welfare state? Are neoliberal agendas inevitably ruling every inch and corner of a society, or can those policies be juggled to a certain extent at an individual or household level? What do we researchers expect and hypothesize, and what are our own personal and professional frameworks for interpretation? In the end, is a glass half empty or half full? This may seem quite abstract - but it comes to life very early and quickly in an internationally comparative qualitative research project. Is a small garden with vegetables just a hobby or a budget release, a resource for gift exchange and nutritional improvement? We might tend to judge it a hobby, or check for cultural and social effects of, say, plot gardening, urban gardening or residual farming, and decide not to follow that track when trying to understand the economy of resilient or non-resilient families. On the other hand, we might overestimate the yields and underestimate the risks of firewood collecting to combat fuel poverty, ignoring the fact that the families observed seldom use dry wood from the forest but prefer destroyed furniture, cardboard and broken plastic items? Are any escapes possible at all from the logics and structures of having just two alternatives, paid labour or living badly from little or no welfare? Is the only way out a meagre life from small wages? Yes, mostly that's the answer from one part of the research team. No, the second part of the team says. Often there is barely a way out, but under certain conditions it can be possible to stay around the poverty line and get by relatively well. Dagdeviren et al. (2016) give an early account of how those difficulties may turn into a theoretical framework, but there is no final solution in sight, either in the social sciences in general, or among the research teams and authors of this book. Chapters 2 and 14 are strongly influenced by the second perspective, and Chapters 5 and 6 by the first one. Nevertheless, of course, this is not only a matter of structure versus action or constraints versus degrees of freedom, Foucault (1977) versus Thompson (1978), structural sociology versus ethnography and anthropology, but a matter of data. On the one hand, the nature of 
the project did not allow for in-depth quantitative case studies on household budget and income development, and, on the other hand, the project could not go further into generalization, such as through a representative survey, but had to stick to just identifying practices, action patterns, and their functional relations (also in symbolic and cultural terms). Quantitative household case studies and representative surveying on socioeconomic resilience will have to be done by other researchers or at another time.

Thus, the question partly has to remain open, calling for further research, and we have to live with a kind of ambiguity. It is possible to do better than others in poverty and crisis, but the conditions and resources are difficult to obtain. Many of the few resilient households observed do just cope better, few of them improve by transforming their conditions, and even fewer of them manage to leave the poverty zone. But where a good level of common goods, networks, cultural 'capital' exists, people may indeed develop resilient patterns of living in or around poverty, and reduce the need for welfare-provided income support.

When finishing the work on this book's manuscript in mid-2020, we found ourselves in the midst of the next European and worldwide crisis caused by the Covid-19 virus. In responding to this crisis, the question of resilience has arisen frequently and loudly. The resilience of cities and regions, healthcare provision and infrastructure, decision-making systems and procedures - such critical infrastructures in this crisis - are determining the level of suffering and loss that we are encountering. And poverty and social inequality seem to highly determine exposure and harm levels of people and families confronted with Covid-19. We dare say that some of the findings in the chapters of this book, which we identify as relevant for poor households, can apply to exploring resilience for a greater diversity of groups confronted by, and responding to, Covid-19 (see Chapter 17). We hope that resilient and non-resilient poor households, the practitioners who support them, as well as scientists and policy makers concerned with poverty issues will benefit from the findings and discussions contained in this book.

\section{NOTES}

1. As a consequence, the concept of family as used here excludes all kinds of institutional cohabitation or residential living, like in a prison, a hospital, a nursing home, a shelter, a flat shared for mere economic reasons, or a boarding school, no matter if the inmates talk about themselves as a family. As one main difference to companies and economic establishments, the primary outcome of a family is the life and wellbeing of the family itself. See also the EU definition of family, https://ec.europa.eu/eurostat/statistics-explained/index.php/Glossary:Household _-_social_statistics (accessed 19 August 2020). 
2. For a recent overview of research on the prevalence of poverty in Europe and its quantitative measurement, see Nolan (2018).

\section{REFERENCES}

Antonovsky, A. (1996), 'The salutogenic model as a theory to guide health promotion', Health promotion international 11(1): 11-18.

Béné, C., Mills, D. J., Raji, A., Kodio A., Morand, P., Andrew, N., Evans, L., Ovie, S., Tafida, A., Sinaba, F. and Lemoalle, J. (2011), 'Testing resilience thinking in a poverty context: experience from the Niger River basin', Global Environmental Change 21(4): 1173-84.

Crouch, C. (2011), The strange non-death of neo-liberalism, Cambridge: Polity Press.

Dagdeviren, H., Donoghue, M. and Promberger, M. (2016), 'Resilience, hardship and social conditions', Journal of Social Policy 45(1):1-20.

Dagdeviren, H., Donoghue, M. and Meier, L. (2017), 'The narratives of hardship: the new and the old poor in the aftermath of the 2008 crisis in Europe', The Sociological Review 65(2): 369-85.

Dolan, P. (2012), 'Travelling through social support and youth civic action on a journey towards resilience', in Ungar, M. (ed.), The social ecology of resilience, New York, NY: Springer, pp. 357-66.

Elder, G. H. (1998), 'The life course as developmental theory', Child Development 69(1): 1-12.

Esping-Andersen, G. (1989), The three worlds of welfare capitalism, Cambridge: Polity Press.

Flick, U. (2011), Triangulation. Eine Einführung, 3. aktualisierte Auflage, Wiesbaden: VS-Verlag.

Flick, U., Hirseland, A. and Hans, B. (2018), 'Walking and talking integration: Triangulation of data from interviews and go-alongs for exploring immigrant welfare recipients' sense(s) of belonging', Qualitative Inquiry 25(8): 799-810.

Foucault, M. (1977), Discipline and punish: the birth of the prison, New York: Pantheon Books.

Frankl, V. E. (1985[1946]), Man's search for meaning, New York: Simon and Schuster.

Glaser, B. G. and Strauss, A. L. (1967), The discovery of grounded theory: Strategies for qualitative research, Chicago: Aldine Pub. Co.

Harper, D. (2002), 'Talking about pictures: A case for photo elicitation', Visual studies 17(1): 13-26.

Haslanger, S. (2018), 'What is a social practice?', Royal Institute of Philosophy Supplements 82: 31-47.

Hirseland, A. and Ramos Lobato, P. (2010), Armutsdynamik und Arbeitsmarkt: Entstehung, Verfestigung und Überwindung von Hilfebedürftigkeit bei Erwerbsfähigen, Nürnberg: IAB-research report, 03/2010.

Jackson, T. (2009), Prosperity without growth: Economics for a finite planet, London: Routledge.

Kirk, J., Contrepois, S. and Jefferys, S. (2011), Changing work and community identities in European regions, Basingstoke: Palgrave Macmillan.

Kolb, B. (2008), 'Involving, sharing, analysing - potential of the participatory photo interview', Forum Qualitative Social Research 9(3): 12.

Lohmann, H. and Andreß, H.-J. (2008), 'Explaining in-work poverty within and across countries', in H. J. Andreß and H. Lohmann (eds.), The Working Poor in Europe, 
Employment, Poverty and Globalization, Cheltenham, UK and Northampton, MA, USA: Edward Elgar Publishing, pp. 293-314.

Lösel, F. and Bender, D. (2003), 'Resilience and protective factors', in D. P. Farrington and J. W. Coid (eds.), Prevention of adult antisocial behavior, Cambridge: Cambridge University Press, pp. 130-204.

Malcolmson, J. M. (1989), 'Ways of getting a living in eighteenth-century England', in R. E. Pahl (ed.), On work. Historical, comparative and theoretical approaches, Reprint, Oxford: Blackwell, pp. 48-60.

Masten, A. S. (2001), 'Ordinary magic: Resilience processes in development', American Psychologist 56(3): 227.

Nolan, B. (2018), 'Poverty and social exclusion in the European Union', in P. Kennett and N. Lendvai-Bainton (eds.), Handbook of European Social Policy, Cheltenham, UK and Northampton, MA, USA: Edward Elgar Publishing, pp. 97-114.

Nolan, B. and Whelan, C. T. (2018), 'Poverty and social exclusion indicators in the European Union: The role of non-monetary deprivation indicators', in R. Carmo, C. Rio and M. Medgyesi (eds.), Reducing Inequalities: A Challenge for the European Union?, Cham: Palgrave Macmillan, pp. 97-114.

Noland, C. M. (2006), 'Auto-photography as research practice: Identity and self-esteem research', Journal of Research Practice 2(1): M1.

Promberger, M. (2015), 'Nine years of Hartz IV - a welfare reform under scrutiny', Cuadernos de relaciones laborales 33(1): 35-63.

Promberger, M. (2017), Resilience among vulnerable households in Europe. Questions, concept, findings and implications, Nuremberg: Institute for Employment Research, IAB Discussion Paper No 12/2017.

Revilla, J. C., Martín, P. and de Castro, C. (2018), 'The reconstruction of resilience as a social and collective phenomenon: poverty and coping capacity during the economic crisis', European Societies 20(1): 89-110.

Sachße, C. and Tennstedt, F. (1992), Geschichte der Armenfürsorge in Deutschland. Der Wohlfahrtsstaat im Nationalsozialismus, Bd. 3, Stuttgart: Kohlhammer.

Schütze, F. (1983), 'Biographieforschung und narratives Interview', Neue Praxis, 13(3): 283-93.

Sennett, R. (2012), Together: The rituals, pleasures and politics of cooperation, New Haven, CT: Yale University Press.

Simmel, G. (1992[1908]), 'Der Arme', in G. Simmel (ed.), Soziologie. Untersuchungen über die Formen der Vergesellschaftung, Gesamtausgabe Band II, Frankfurt/M.: Suhrkamp, pp. 512-55.

Taylor-Gooby, P., Leruth B. and Chung, H. (eds.) (2017), After austerity: Welfare state transformation in Europe after the Great Recession, New York: Oxford University Press.

Thompson, E. P. (1978), The poverty of theory and other essays, London: Merlin Press.

Ungar, M. and Liebenberg, L. (2005), 'The International Resilience project, a mixed methods approach to the study of resilience across cultures', in M. Ungar (ed.), Handbook for working with children and youth: Pathways to resilience across cultures and contexts, Thousand Oaks, CA: Sage, pp. 211-29.

Vuojala-Magga, T., Turunen, M., Ryyppö, T. and Tennberg, M. (2011), 'Resonance strategies of Sámi reindeer herders in northernmost Finland during climatically extreme years', Arctic 64(2): 227-41.

Wallman, S. (1979), Social anthropology of work, London: Academic Press.

Wuggenig, U. (1990), 'Die Photobefragung als projektives Verfahren', Angewandte Sozialforschung 16: 109-29. 